\title{
Orange Rust Effects on Leaf Photosynthesis and Related Characters of Sugarcane
}

Duli Zhao, Neil C. Glynn, Barry Glaz, Jack C. Comstock, and Sushma Sood, USDA-ARS, Sugarcane Field Station, 12990 U.S. Highway 441 North, Canal Point, FL 33438

\begin{abstract}
Zhao, D., Glynn, N. C., Glaz, B., Comstock, J. C., and Sood, S. 2011. Orange rust effects on leaf photosynthesis and related characters of sugarcane. Plant Dis. 95:640-647.

Orange rust of sugarcane (Saccharum spp. hybrids), caused by Puccinia kuehnii, is a relatively new disease in the Western Hemisphere that substantially reduces yields in susceptible sugarcane genotypes. The objective of this study was to determine the physiological mechanisms of orange rust-induced reductions in sugarcane growth and yield by quantifying effects of the disease on leaf SPAD index (an indication of leaf chlorophyll content), net photosynthetic rate, dark respiration, maximum quantum yield of $\mathrm{CO}_{2}$ assimilation, carbon fixation efficiency, and the relationships between these leaf photosynthetic components and rust disease ratings. Plants growing in pots were inoculated with the orange rust pathogen using a leaf whorl inoculation method. A disease rating was assigned using a scale from 0 to 4 with intervals of 0.5 . At disease ratings $\geq 2$, the rust-infected leaf portion of inoculated

plants showed significant reductions in SPAD index, maximum quantum yield, carbon fixation efficiency, stomatal conductance, leaf transpiration rate, and net photosynthetic rate; but the rusted portion of the infected leaves had increased intercellular $\mathrm{CO}_{2}$ concentration and leaf dark respiration rate. Although leaf SPAD index, photosynthetic rate, stomatal conductance, and transpiration rate at the rust-infected portion decreased linearly with increased rust rating, the effect of orange rust on photosynthetic rate was much greater than that on stomatal conductance and transpiration. Unlike earlier reports on other crops, reduction in leaf photosynthesis by orange rust under low light was greater than that under high light conditions. These results help improve the understanding of orange rust etiology and physiological bases of sugarcane yield loss caused by orange rust.
\end{abstract}

Sugarcane (Saccharum spp. hybrids) is an important crop for sugar and biofuels worldwide because of high stalk sucrose content and high biomass production due to its $\mathrm{C} 4$ photosynthesis pathway. More than 157,000 ha of sugarcane were grown in Florida in 2008 (34), accounting for approximately $48 \%$ of the U.S. sugarcane production. Currently, leaf rust diseases are challenges for sugarcane production in the United States (40). Sugarcane orange rust (Puccinia kuehnii (W. Krüger) E.J. Butler) has resulted in considerable economic loss in Australia $(10,25)$. This disease was reported in Florida for the first time in 2007 (14). Orange rust has since caused substantial sugarcane yield loss in Florida (33), because several of the widely planted commercial cultivars are susceptible to this disease (J. C. Comstock, personal communication). Orange rust has also been found in sugarcane growing in the Central American countries of Guatemala (30), Costa Rica (13), Nicaragua (13), Mexico (17), El Salvador (17), Panama (17), and more recently Brazil (2) and Cuba (31).

Crop yields are closely related to canopy radiation interception (green leaf area index), carbon assimilation (leaf photosynthetic rate), and photo-assimilate translocation and partitioning (18). Previous studies suggested that chlorosis and necrosis are common symptoms of infections caused by foliar pathogens. Chlorosis resulting from infection of foliar pathogens is related to chlorophyll loss $(44,48)$. Fungi causing foliar necrotic reactions usually affect leaf photosynthesis $(11,28,36,37,41,44)$. Decreases in physiologi-

Corresponding author: D. Zhao, E-mail: duli.zhao@ars.usda.gov

Use of trade or product names is for informational purposes only and does not imply endorsement by the United States Department of Agriculture to the exclusion of any other product that may be suitable.

Accepted for publication 1 February 2011.

doi:10.1094/PDIS-10-10-0762

This article is in the public domain and not copyrightable. It may be freely reprinted with customary crediting of the source. The American Phytopathological Society, 2011. cal characters, such as reduction in green leaf area index and decline in functional chloroplasts with resulting reduced photosynthetic rate, have been associated with crop yield loss (1,5).

When estimating yield loss by a specific disease, it is appropriate to integrate physiological information into crop-loss studies $(4,5,32)$. Biemelt and Sonnewald (9) reviewed plant-microbe interactions to probe regulation of plant carbon metabolism from the source-sink relation of plants. Sugarcane yield loss caused by orange rust has been assessed in Australia $(10,25)$ and the United States (33). However, physiological mechanisms of the rust effect on sugarcane yield remain unclear. The quantitative determination of effects of a specific disease on the physiology of individual leaves is the first step toward a broader understanding of crop yield losses (5).

Studies on other crops, including bean (Phaseolus vulgaris), wheat (Triticum aestivum), grape (Vitis vinifera), and rice (Oryza sativa), have shown that fungal infections can reduce crop productivity by reducing the photosynthetic efficiency of the remaining green leaf area $(3,6,27,35)$. However, photosynthesis in rustinfected leek (Allium porrum) leaves did not differ from the uninfected controls in the region between pustules, although significant reduction in photosynthesis was detected in pustule regions (36). Early research (23) found that inhibition of photosynthesis in infected tissue can be compensated partially by stimulation in organs at a distance from the infected leaf. In a legume crop, following rust inoculation of the lower leaves of broad bean (Vicia faba) plants, photosynthetic rate was substantially reduced in the lower, rusted leaves, but net photosynthesis was significantly increased in the upper, uninfected leaves of the inoculated plants compared with the noninoculated controls (28).

Effects of rust diseases on leaf photosynthesis vary with the types of pathogens, disease severity, and host plant species and/or crop genotypes. Because sugarcane orange rust is a relatively new disease in the Western Hemisphere, there is no report for responses of sugarcane leaf carbon exchange and photosynthetic radiation use and carbon use efficiencies to orange rust. It was hypothesized that orange rust causes reduction in leaf photosynthesis of sugarcane not only for rusted areas of leaves, but also for remaining 
green portions of infected leaves and for the upper canopy of noninfected leaves. An outdoor pot experiment was conducted to test this hypothesis. The specific objectives of the study were to identify physiological mechanisms involved in the orange rust-induced reduction in sugarcane growth and yield by quantifying effects of the disease on leaf chlorophyll level (SPAD index), photosynthesis, and related characteristics and to determine relationships between these leaf photosynthetic components and disease ratings.

\section{Materials and Methods}

Plant culture and treatment. A pot study was conducted at the USDA-ARS Sugarcane Field Station $\left(26.91^{\circ} \mathrm{N}, 80.61^{\circ} \mathrm{W}\right)$, Canal Point, FL, in 2009. Noninoculated (control) and P. kuehnii-inoculated plants were compared using four sugarcane genotypes. The genotypes, 'CP 72-2086' (26), 'CP 88-1762' (43), 'CP 89-2143' (19), and 'CPCL 99-4455' (15), are commercial cultivars in Florida and vary in susceptibility to orange rust. Single-bud stalk sections of each genotype were planted in 4.6-liter pots $(18 \mathrm{~cm}$ in both diameter and height) filled with a potting soil mixed with new peat and pine bark fines $(\mathrm{vol} / \mathrm{vol}=9: 1)$ and $5 \%(\mathrm{wt})$ fine sand (Florida Potting Soils, Orlando, FL) on 24 July 2009. To ensure consistent conditions of soil, water, and nutrients for inoculated and noninoculated (control) plants, two stalk sections of the same genotype were planted in each pot. There were two plants per pot (one inoculated and one not inoculated). Pots were arranged on outdoor benches under ambient conditions. A combination fertilizer $(\mathrm{N}-$ $\mathrm{P}_{2} \mathrm{O}_{5}-\mathrm{K}_{2} \mathrm{O}=10-10-10$; Frick Services Inc., Sugar Grove, IL) of $4 \mathrm{~g}$ pot $^{-1}$ was applied 30 days after planting. During the experiment, all pots were watered daily.

Orange rust urediniospores produced in pustules on the abaxial side of symptomatic leaves were collected from different sugarcane cultivars in several production fields and mixed together in equal amounts the day before inoculation according to Sood et al. (40). Sterile distilled water with $0.002 \%$ (vol/vol) 1-nonanol was added to rust urediniospores so the urediniospore concentration in the solution was approximately 100,000 urediniospores $\mathrm{ml}^{-1}$. When sugarcane plants had five leaves on the primary shoot (35 days after planting), inoculations were performed by placing $0.5 \mathrm{ml}$ of the spore suspension in the leaf whorl of each inoculated plant in late afternoon using a pipette. Mean temperature was $27^{\circ} \mathrm{C}$ and relative humidity was $89 \%$ on the inoculation date (29 August 2009) at the experimental location. The control plants at the same time received the same amount of distilled water with 1-nonanol but without rust urediniospores. After 4 weeks of weekly rust disease evaluations and measurements of leaf photosynthesis characteristics, old leaves, including the infected leaf, below the uppermost fully expanded leaf (i.e., the top visible dewlap [TVD] leaf) were trimmed from all plants to provide suitable plants for a second disease inoculation and for further determination of leaf photosynthesis light- and $\mathrm{CO}_{2}$-response curves. The second inoculation was applied 1 day after trimming. Photosynthesis responses to light intensity and $\mathrm{CO}_{2}$ concentration were assessed approximately 4 weeks after the second inoculation.

Measurements. After leaf emergence, rust symptoms on susceptible plants appeared as bands of pustules on portions of leaves that were inoculated with urediniospores in the whorl (Fig. 1). Disease assessment started 1 week after each inoculation and continued approximately weekly for 4 weeks. Disease reaction was rated on a modified scale from 0 to 4 with intervals of 0.5 according to Sood et al. (40). In general, inoculated plants were considered resistant with rust rating 0 to 1 , moderately resistant with rating 2, and susceptible with rating of at least 3 (Fig. 1).

On the same dates as disease assessments after the first inoculation, leaf SPAD index (an indication of leaf chlorophyll content) and the leaf photosynthetic components, net photosynthetic rate $(\mathrm{Pn})$, stomatal conductance $\left(\mathrm{g}_{\mathrm{s}}\right)$, leaf transpiration rate $(\mathrm{Tr})$, intercellular $\mathrm{CO}_{2}$ concentration $(\mathrm{Ci})$, as well as leaf temperature and leaf-to-air water vapor pressure deficit (VPD), were measured between 0930 and $1400 \mathrm{~h}$ (EDST) from TVD leaves (i.e., noninoculated and uppermost fully expanded leaf) to determine if rust inoculation affected photosynthetic properties of noninfected leaves on inoculated plants. Leaf SPAD index was measured with a Minolta 02 SPAD meter (Minolta Co., LTD., Japan). A LI-6400XT portable photosynthesis system (LI-COR Inc., Lincoln, NE) was used to measure leaf photosynthetic components according to Zhao et al. (46). When measuring leaf photosynthesis, the photosynthetically active radiation (PAR) in the leaf chamber, provided by the 6400-02 LED light source, was set to $1,500 \mu \mathrm{mol} \mathrm{m} \mathrm{m}^{-2} \mathrm{~s}^{-1}$, relative humidity was adjusted to near ambient level (approximately 70\%), and leaf chamber $\mathrm{CO}_{2}$ concentration was set to $380 \mu$ liter $^{-1}$

At the last disease assessment, 4 weeks after the first inoculation, rust symptoms appeared as bands of pustule on inoculated leaves of susceptible plants, but there were no visible disease symptoms at the lower and upper portions of the pustule band for all inoculated leaves (Fig. 1). SPAD index and photosynthesis components were measured at the upper, lower, and pustule band (infected) portions of inoculated leaves to identify differences among the rust ratings within and among the three portions of the same leaves (Fig. 1).

Approximately 4 weeks after the second inoculation, photosynthesis light- and $\mathrm{CO}_{2}$-response curves were measured at the

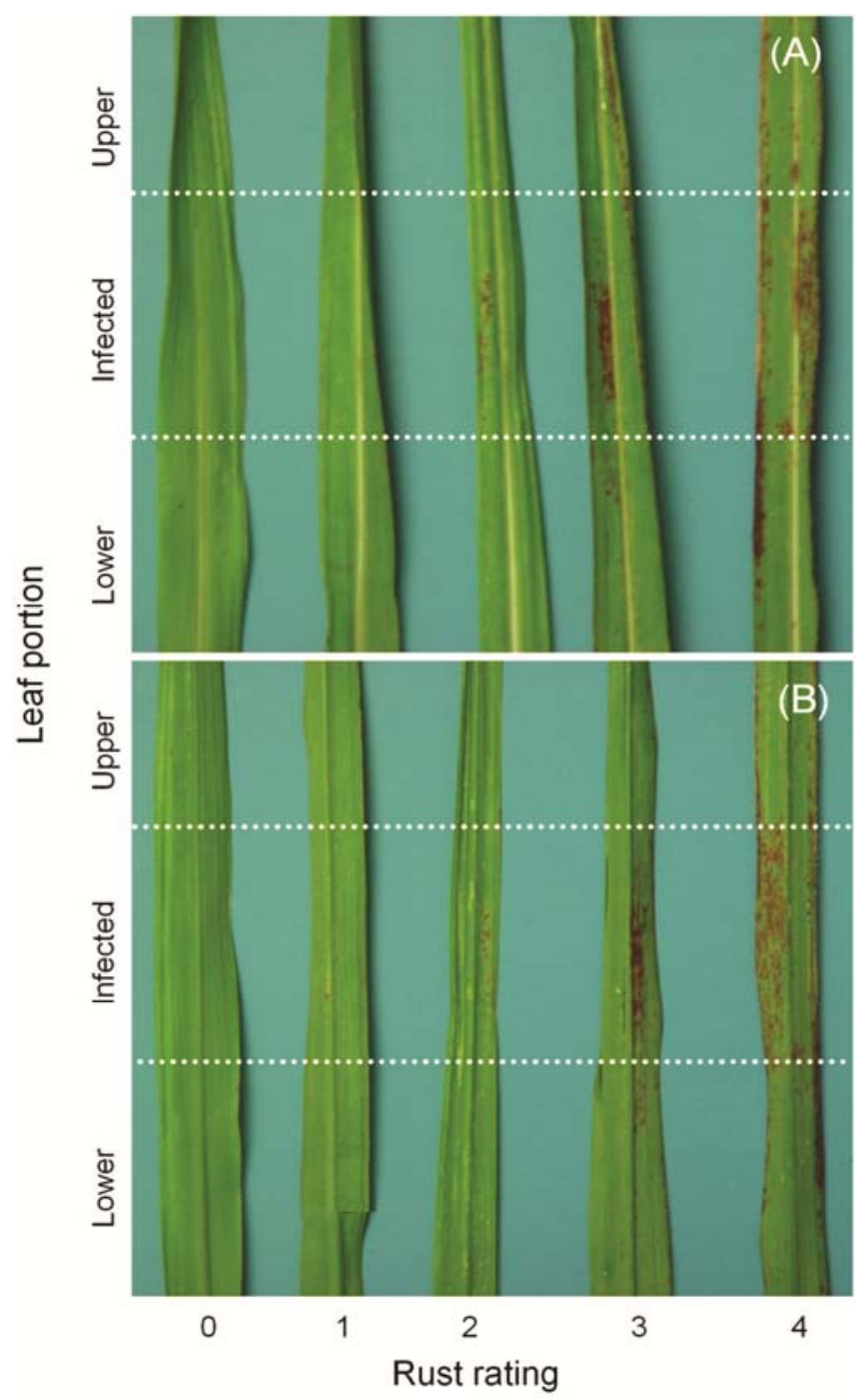

Fig. 1. Typical sugarcane leaves infected by Puccinia kuehnii with disease ratings 0 (control), 1, 2, 3, and 4. Leaf SPAD index, net photosynthetic rate, stomatal conductance, transpiration rate, and intercellular $\mathrm{CO}_{2}$ concentration were measured at the infected portion and lower and upper portions of infected leaves. The figure also demonstrates the characteristics of each disease level on $\mathbf{A}$, adaxial and $\mathbf{B}$, abaxial surfaces. Symptoms of rust ratings $0,1,2,3$, and 4 can be described as no symptoms, mostly white flecks with a few brown flecks, mostly brown flecks, all brown flecks and flecks run together to form brown lesions with few pustules, and mostly lesions with many pustules, respectively. 
inoculated portions of leaves with disease ratings of 0,3 , and 4 using the "Auto Programs" of LI-6400XT portable photosynthesis system. Because measurements of light- and $\mathrm{CO}_{2}$-response curves were time-consuming, we were unable to measure them in all treatment plants. Three typical replicate plants for each rust rating were selected from CP 72-2086 and CP 88-1762 to determine relationships between leaf $\mathrm{Pn}$ and PAR or $\mathrm{CO}_{2}$ concentration as affected by rust infection. These two genotypes were used because they had comparable leaf Pn based on earlier measurements (Table 1) and enough typically infected leaves for measurements of photosynthesis light- and $\mathrm{CO}_{2}$-response curves. These measurements were on infected portions of inoculated leaves (Fig. 1) from 1000 to $1400 \mathrm{~h}$ on five successive days.

When measuring leaf photosynthesis light-response curves, air temperature inside the leaf chamber was set to $32^{\circ} \mathrm{C}$, relative humidity was set to approximately $70 \%$, and $\mathrm{CO}_{2}$ concentration was set to $380 \mu$ liter $^{-1}$ based on ambient conditions during measurements at the location. The PAR was gradually decreased from 1,800 to $0 \mu \mathrm{mol} \mathrm{m} \mathrm{m}^{-2} \mathrm{~s}^{-1}$ in nine steps $(1,800,1,500,1,000,500$, 200, 100, 50, 20, and $0 \mu \mathrm{mol} \mathrm{m} \mathrm{m}^{-2} \mathrm{~s}^{-1}$ ). Stomatal conductance, $\mathrm{Ci}$, Tr, leaf temperature, and VPD were recorded while measuring photosynthesis light-response curves. Values of leaf dark respiration ( $\mathrm{Rd}$ ) rate, light compensation point (LCP), and the maximum quantum yield of $\mathrm{CO}_{2}$ assimilation (MQY) were obtained by the initial linear regression of the last four levels of light intensities (PAR: 0, 20, 50, and $100 \mu \mathrm{mol} \mathrm{m} \mathrm{m}^{-2} \mathrm{~s}^{-1}$ ) and the respective gas exchange rates $(42,47)$. Based on linear regression, the absolute value of gas exchange rate, when PAR $=0$, was defined as leaf $\mathrm{Rd}$ rate; the value of PAR, when gas exchange rate $=0$, was defined as LCP (47); and the slope of the regression line was defined as MQY (42).

When measuring leaf photosynthesis $\mathrm{CO}_{2}$-response curves, air temperature inside the leaf chamber was set to $32^{\circ} \mathrm{C}$, relative humidity to approximately $70 \%$, and PAR to $1,500 \mu \mathrm{mol} \mathrm{m} \mathrm{m}^{-2} \mathrm{~s}^{-1}$. The $\mathrm{CO}_{2}$ concentration in the leaf chamber was changed in eight steps $\left(400,600,300,200,100,50,40\right.$, and $\left.400 \mu l_{l i t e r}{ }^{-1}\right)$, and leaf Pn was determined at each step by slowly adjusting $\mathrm{CO}_{2}$ concentration. The slope of the straight line of the photosynthesis $\mathrm{CO}_{2^{-}}$ response linear face was defined as carbon fixation efficiency (CFE) of leaf photosynthesis. Values of CFE were obtained by linear regression of the first four $\mathrm{CO}_{2}$ concentrations from the lowest $\mathrm{CO}_{2}$ level (i.e., 40, 50, 100, and $200 \mu \mathrm{l}$ liter $^{-1}$ ) and the respective leaf gas exchange rates.

Following all physiological measurements, DNA was extracted from the rust-infected lesions on CP 72-2086 and CP 88-1762 according to Glynn et al. (20) to ensure the disease was caused by $P$. kuehnii. Extracts were tested for presence of the orange rust pathogen and the sugarcane brown rust pathogen $P$. melanocephala using real-time PCR assays for each pathogen (20). The PCR test produced positive $P$. kuehnii signals and negative $P$. melanocephala signals for all samples confirming that $P$. kuehnii was the only rust pathogen present.

Experimental design and data analysis. The experimental design was a randomized complete block with a split-plot arrange-

Table 1. Net photosynthetic rate of top visible dewlap leaf for noninoculated (control) and inoculated plants of four sugarcane genotypes at 7,14 , and 18 days after inoculation ${ }^{\mathrm{z}}$

\begin{tabular}{|c|c|c|c|c|}
\hline \multirow[b]{2}{*}{ Genotype } & \multirow[b]{2}{*}{ Treatment } & \multicolumn{3}{|c|}{ Photosynthetic rate $\left(\mu \mathrm{mol} \mathrm{m} \mathrm{m}^{-2} \mathrm{~s}^{-1}\right)$} \\
\hline & & Day 7 & Day 14 & Day 18 \\
\hline \multirow[t]{2}{*}{ CP 72-2086 } & Control & $19.4 \pm 1.3 \mathrm{ab}$ & $19.3 \pm 1.3 \mathrm{ab}$ & $20.3 \pm 1.4 \mathrm{ab}$ \\
\hline & Inoculated & $19.7 \pm 1.4 \mathrm{ab}$ & $17.5 \pm 1.6 b$ & $20.2 \pm 2.2 \mathrm{a}$ \\
\hline \multirow[t]{2}{*}{ CP $88-1762$} & Control & $21.2 \pm 1.2 \mathrm{a}$ & $22.3 \pm 1.2 \mathrm{a}$ & $21.7 \pm 2.1 \mathrm{a}$ \\
\hline & Inoculated & $22.0 \pm 1.0 \mathrm{a}$ & $22.7 \pm 1.3 \mathrm{a}$ & $20.7 \pm 1.7 \mathrm{a}$ \\
\hline \multirow[t]{2}{*}{ CP $89-2143$} & Control & $17.3 \pm 1.2 \mathrm{~b}$ & $18.2 \pm 1.0 \mathrm{~b}$ & $16.5 \pm 0.7 b$ \\
\hline & Inoculated & $18.0 \pm 1.1 \mathrm{~b}$ & $20.1 \pm 1.1 \mathrm{~b}$ & $14.8 \pm 1.0 \mathrm{~b}$ \\
\hline \multirow{2}{*}{$\begin{array}{l}\text { CPCL 99- } \\
4455\end{array}$} & Control & $19.8 \pm 1.0 \mathrm{ab}$ & $20.1 \pm 0.8 \mathrm{ab}$ & $18.9 \pm 0.9 \mathrm{ab}$ \\
\hline & Inoculated & $19.6 \pm 0.9 \mathrm{ab}$ & $20.3 \pm 1.1 \mathrm{ab}$ & $20.8 \pm 1.4 \mathrm{a}$ \\
\hline
\end{tabular}

${ }^{\mathrm{z}}$ Data are means $\pm \mathrm{SE}(n=12)$. Means followed by the same letter within a column are not significantly different at $P=0.05$ level using LSD test. ment of pots with 12 replications (pots) for each genotype. Plant genotype was the main plot and the rust inoculation treatment the subplot. To test plant genotype differences in response to orange rust inoculation and to compare leaf photosynthetic components between inoculated and noninoculated treatments, significance of each fixed effect was analyzed using the MIXED procedure of SAS (38). Replication was considered as a random effect and genotype and inoculation were considered as fixed effects. Measurement dates for Pn of TVD leaves were considered repeated. If the hypothesis of equal means for a measured variable between treatments was rejected by the $F$ test, then data means were separated with the LSD at $P=0.05$. The LSD values were calculated with the SE values generated by the Diff option in the MIXED procedure.

Linear regression was used to determine relationships between rust rating and leaf SPAD index or each leaf photosynthesis component (Pn, $\mathrm{g}_{\mathrm{s}}, \mathrm{Tr}$, and $\mathrm{Ci}$ ), measured at the lower, upper, and infected portions of inoculated leaves 4 weeks after the first inoculation as well as leaf Rd rate, LCP, MQY, and CFE from photosynthesis light- and $\mathrm{CO}_{2}$-response curves described above. When SPAD index and photosynthesis were measured on inoculated leaves 4 weeks after inoculation, there were no statistical differences in these variables between genotypes. Therefore, data were pooled over plant genotypes and averaged by the disease ratings to determine the relationships between rust rating and leaf photosynthetic parameters. The photosynthetic light-response curves were fitted using a least-square solution to a nonrectangular hyperbola according to Ŏgren and Even (29). Best-fit nonlinear or quadratic regressions were employed to determine relationships between other physiological variables $\left(\mathrm{g}_{\mathrm{s}}, \mathrm{Ci}\right.$, and $\left.\mathrm{Tr}\right)$ and PAR and between leaf $\mathrm{CO}_{2}$ exchange rates and $\mathrm{CO}_{2}$ concentration using SAS (38).

\section{Results}

Photosynthesis of top visible dewlap leaves. Net photosynthetic rates $(\mathrm{Pn})$ of TVD leaves from the noninoculated control and inoculated plants were measured 7, 14, and 18 days after inoculation (Table 1). Overall, genotype significantly affected leaf $\operatorname{Pn}(P<$

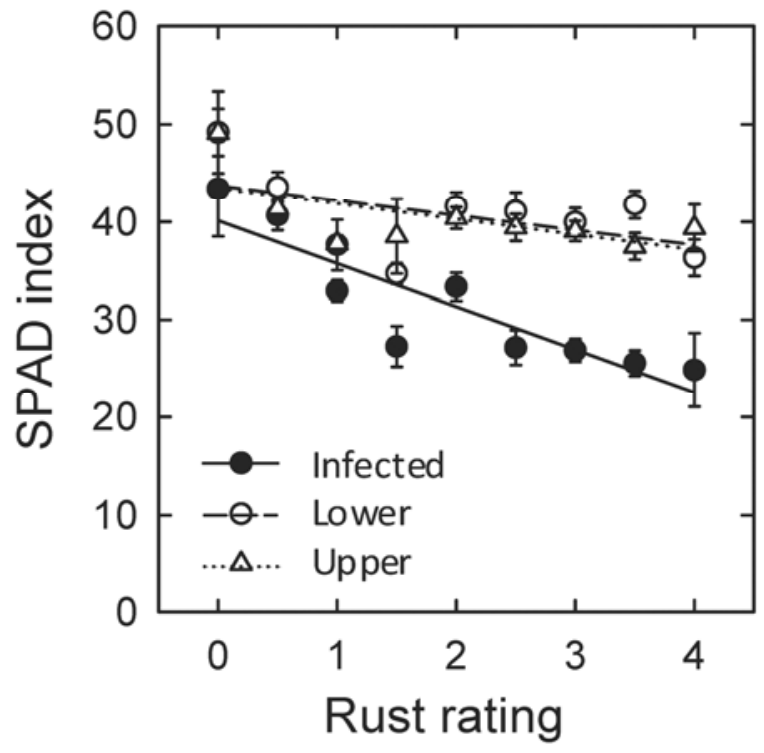

\begin{tabular}{lcccc}
\hline Position & Intercept & Slope & $r^{2}$ & $P>F$ \\
\hline Infected & 40.12 & -4.38 & 0.785 & 0.0015 \\
Lower & 43.71 & $-1,53$ & 0.236 & 0.1581 \\
Upper & 43.64 & -1.58 & 0.371 & 0.0815 \\
\hline
\end{tabular}

Fig. 2. Leaf SPAD index response to increasing orange rust severity (indicated by disease rating). Measurements were taken at the infected, lower, and upper portions of inoculated leaves 4 weeks after inoculation. Data are pooled over genotypes and presented as means $\pm \mathrm{SE}$ by the rust rating. 
0.01), but measurement date or inoculation treatment did not affect leaf Pn. The genotype $\times$ date interaction was significant $(P=0.05)$, but other two- or three-way interactions were not significant (data not shown). The LSD test indicated that only CP 88-1762 had significantly greater leaf Pn than CP 89-2143 at all measurement dates. These two genotypes did not differ from either CP 72-2086 or CPCL 99-4455 in leaf Pn except for the inoculated CP 72-2086 at 14 days after inoculation with lower Pn than CP 88-1762 (Table 1).

SPAD index and photosynthesis of rust infected leaves. The SPAD index measured on the infected area of the inoculated leaves linearly and significantly decreased as disease rating increased $\left(r^{2}\right.$ $=0.785$ and $P<0.001$ ). Leaf SPAD index decreased by 4.4 for each unit increase in the rust rating (Fig. 2). The infected leaf portion with rust rating 4 had a $44 \%$ less SPAD index value compared with the control. When measurements were taken on lower and upper portions (see Fig. 1) of infected leaves, SPAD indexes declined slightly with increasing rust ratings, but were not signifi- cantly correlated for the lower $\left(r^{2}=0.236\right.$ and $\left.P=0.158\right)$ or upper $\left(r^{2}=0.371\right.$ and $\left.P=0.082\right)$ leaf portions (Fig. 2).

Leaf Pn was not correlated with rust rating when measurements were taken either on the lower or upper portions of infected leaves (Fig. 3A). However, Pn on the rust-infected portion declined linearly with a slope of -2.82 as rust rating increased $(P<0.001)$. Leaf Pn decreased from 25.0 to $13.7 \mu \mathrm{mol} \mathrm{m} \mathrm{m}^{-2} \mathrm{~s}^{-1}$ (decreased by $45 \%$ ) when disease rating increased from 0 to 4 (Fig. 3A). When rust rating reached 2 , Pn had declined by $23 \%(P<0.05)$ compared with the control (rating $=0$ ).

The relationship between $g_{s}$ and rust rating also depended on the portion of the leaf where the measurements were taken. When measurements were taken at the upper or directly infected portions, $\mathrm{g}_{\mathrm{s}}$ declined linearly as rust rating increased $\left(r^{2}=0.502\right.$ and $P<0.05$ for the upper portion and $r^{2}=0.714$ and $P<0.01$ for the infected portion). On the lower portion of the infected leaf, the relationship was not significant (Fig. 3B). Leaf $\operatorname{Tr}$ was more sensitive to rust
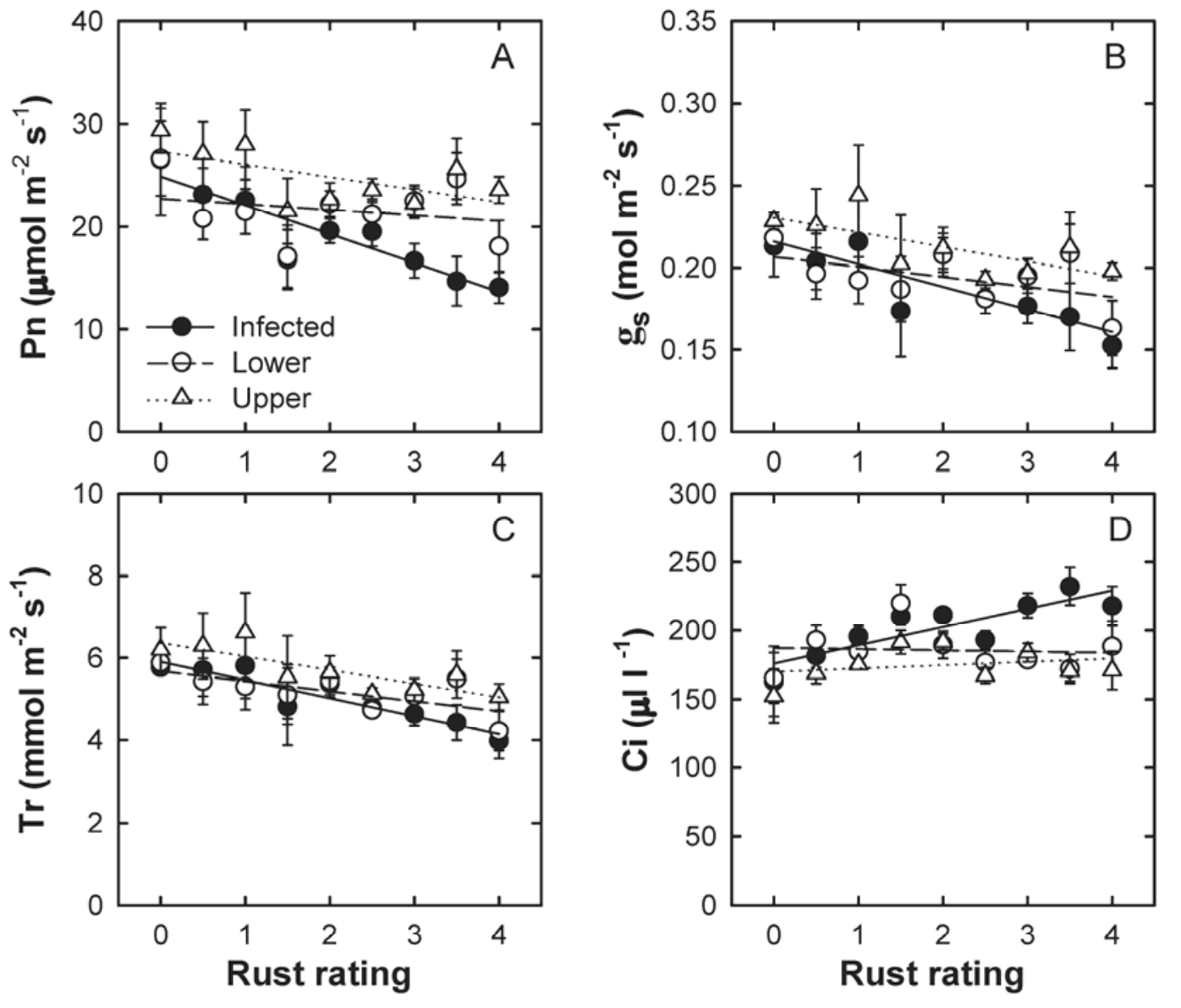

\begin{tabular}{|c|c|c|c|c|c|c|c|c|}
\hline \multirow{2}{*}{ Position } & \multicolumn{4}{|c|}{$\mathrm{Pn}$} & \multicolumn{4}{|c|}{$g_{s}$} \\
\hline & Intercept & Slope & $r^{2}$ & $P>F$ & Intercept & Slope & $r^{2}$ & $P>F$ \\
\hline Infected & 24.95 & -2.82 & 0.848 & 0.0004 & 0.216 & -0.014 & 0.714 & 0.0041 \\
\hline Lower & 22.71 & -0.54 & 0.063 & 0.5137 & 0.207 & -0.006 & 0.261 & 0.1596 \\
\hline Upper & 27.32 & -1.23 & 0.367 & 0.0838 & 0.230 & -0.009 & 0.502 & 0.0328 \\
\hline \multirow{2}{*}{ Position } & \multicolumn{4}{|c|}{$\mathrm{Tr}$} & \multicolumn{4}{|c|}{$\mathrm{Ci}$} \\
\hline & Intercept & Slope & $r^{2}$ & $P>F$ & Intercept & Slope & $r^{2}$ & $P>F$ \\
\hline Infected & 5.922 & -0.445 & 0.861 & 0.0003 & 175.8 & 13.40 & 0.732 & 0.0033 \\
\hline Lower & 5.672 & -0.243 & 0.471 & 0.0414 & 187.1 & -0.90 & 0.006 & 0.8432 \\
\hline Upper & 6.336 & -0.323 & 0.640 & 0.0096 & 169.8 & 2.38 & 0.067 & 0.5018 \\
\hline
\end{tabular}

Fig. 3. Responses of $\mathbf{A}$, leaf net photosynthetic rate $(\mathrm{Pn}), \mathbf{B}$, stomatal conductance $\left(\mathrm{g}_{\mathrm{s}}\right), \mathbf{C}$, transpiration rate $(\mathrm{Tr})$, and $\mathbf{D}$, intercellular $\mathrm{CO}_{2}$ concentration $(\mathrm{Ci})$ to orange rust severity (indicated by disease rating). Measurements were taken at the infected, lower, and upper portions of inoculated leaves 4 weeks after inoculation. Data are pooled over genotypes and presented as means $\pm \mathrm{SE}$ by the rust rating. 
compared to $\mathrm{g}_{\mathrm{s}}$ and decreased significantly on all three leaf portions as the rust rating increased (Fig. 3C). Compared with the control, the rust-infected portion of inoculated leaves with a rust rating of 4 had $26 \%$ lower $\mathrm{g}_{\mathrm{s}}$ and $30 \%$ less $\mathrm{Tr}$. In contrast, $\mathrm{Ci}$ increased linearly with increased rust rating, and this relationship was only detected on diseased portions of inoculated leaves (Fig. 3D). Rust rating had little effect on leaf temperature and VPD (data not shown).

Photosynthesis response to PAR. Leaf Pn responses to light intensity exhibited quadratic increases with increase in PAR and were well fitted using a nonrectangular hyperbola for all treatments (Fig. 4A). As PAR increased from 100 to $1,000 \mu \mathrm{mol} \mathrm{m}^{-2} \mathrm{~s}^{-1}$, leaf Pn increased rapidly and then increased slowly as PAR increased. Leaf Pn did not appear to reach a maximum value even at PAR = $1,800 \mu \mathrm{mol} \mathrm{m} \mathrm{m}^{-2} \mathrm{~s}^{-1}$ (Fig. 4A).

Rust infection ratings of 3 and 4 significantly reduced leaf Pn, and the magnitude of $\mathrm{Pn}$ reduction was associated with the disease rating and light intensity (Fig. 4A). At the same rust rating, effect of rust on leaf Pn was greater at low PAR than at high PAR. When PAR was between 100 and $500 \mu \mathrm{mol} \mathrm{m} \mathrm{m}^{-2} \mathrm{~s}^{-1}$, leaves with rust infected ratings 3 and 4 had 45 and 92\% lower Pn $(P<0.001-$ $0.0001)$, respectively, compared with the controls. At PAR of 1,800 $\mu \mathrm{mol} \mathrm{m} \mathrm{m}^{-1}$, Pn of the infected leaves with ratings 3 and 4 were 33 and $56 \%$, respectively, lower than that of the noninfected leaves $(P$ $<0.01-0.001$ ) (Fig. 4A).

Responses of $g_{s}$ (Fig. 4B) and leaf $\operatorname{Tr}$ (Fig. 4C) to light intensity were similar to those of leaf Pn (Fig. 4A). However, disease had less effect on $g_{s}$ and $\mathrm{Tr}$ than on leaf Pn. Leaves with rust ratings of 3 did not differ from the control in either $\mathrm{g}_{\mathrm{s}}$ or $\mathrm{Tr}$ when PAR was lower than $500 \mu \mathrm{mol} \mathrm{m} \mathrm{m}^{-2} \mathrm{~s}^{-1}$. At PAR of $1,800 \mu \mathrm{mol} \mathrm{m} \mathrm{s}^{-2} \mathrm{~s}^{-1}, \mathrm{~g}_{\mathrm{s}}$ and $\mathrm{Tr}$ of the leaves with rust rating 3 did not differ significantly from those of the noninfected leaves, but $\mathrm{g}_{\mathrm{s}}$ and leaf $\mathrm{Tr}$ at a rust rating of 4 were 44 and $43 \%(P<0.001)$, respectively, lower than those of the control leaves. Intercellular $\mathrm{CO}_{2}$ concentration declined sharply as PAR increased and reached the lowest level when PAR was approximately $1,000 \mu \mathrm{mol} \mathrm{m} \mathrm{m}^{-2} \mathrm{~s}^{-1}$ for both rust-infected and noninfected leaves (Fig. 4D). There were no differences between disease ratings 3 and 4 in $\mathrm{Ci}$ at most levels of PAR, but their $\mathrm{Ci}$ were significantly higher than those of control leaves at all PAR levels $(P<0.001)$. The rust-infected leaves with disease ratings 3 and 4 had 28 to $34 \%$ and 37 to $46 \%$ higher $\mathrm{Ci}$, respectively, than the noninfected control leaves when PAR was between 500 and 1,800 $\mu \mathrm{mol} \mathrm{m} \mathrm{m}^{-2} \mathrm{~s}^{-1}$ (Fig. 4D). During measuring leaf Pn response to PAR, neither leaf temperature nor VPD differed between treatments (data not shown). When PAR decreased from 1,800 to $0 \mu \mathrm{mol} \mathrm{m} \mathrm{m}^{-2} \mathrm{~s}^{-1}$, leaf temperature slightly increased from 31.5 to $32.0^{\circ} \mathrm{C}$ and VPD from 2.19 to $2.34 \mathrm{kPa}$, averaged across treatments.

Photosynthesis response to $\mathrm{CO}_{2}$. Sugarcane leaf Pn rapidly increased as $\mathrm{CO}_{2}$ concentration increased, and their relationship was best described by quadratic regression (Fig. 5). Similar to the lightresponse curves of $\mathrm{Pn}$, the rust disease significantly reduced leaf $\mathrm{Pn}$ at all $\mathrm{CO}_{2}$ concentrations. When $\mathrm{CO}_{2}$ concentration in the leaf chamber increased from 40 to $600 \mu \mathrm{liter}^{-1}$, Pn of noninfected control leaves increased from 4.2 to $48.0 \mu \mathrm{mol} \mathrm{m} \mathrm{m}^{-2} \mathrm{~s}^{-1}$, but only increased from 1.8 to $26.5 \mu \mathrm{mol} \mathrm{m}{ }^{-2} \mathrm{~s}^{-1}$ for leaves with a rust rating of 3 and from 0.5 to $17.3 \mu \mathrm{mol} \mathrm{m} \mathrm{m}^{-2} \mathrm{~s}^{-1}$ for leaves with a rust rating of 4 (Fig. 5). Averaged across $\mathrm{CO}_{2}$ concentrations, the leaves with rust ratings of 3 and 4 had 51 and $72 \%$ lower leaf $\mathrm{Pn}$, respectively, when compared to noninfected control leaves.

Dark respiration, LCP, MQY, and CFE. Orange rust significantly increased leaf Rd rate but decreased photosynthetic MQY
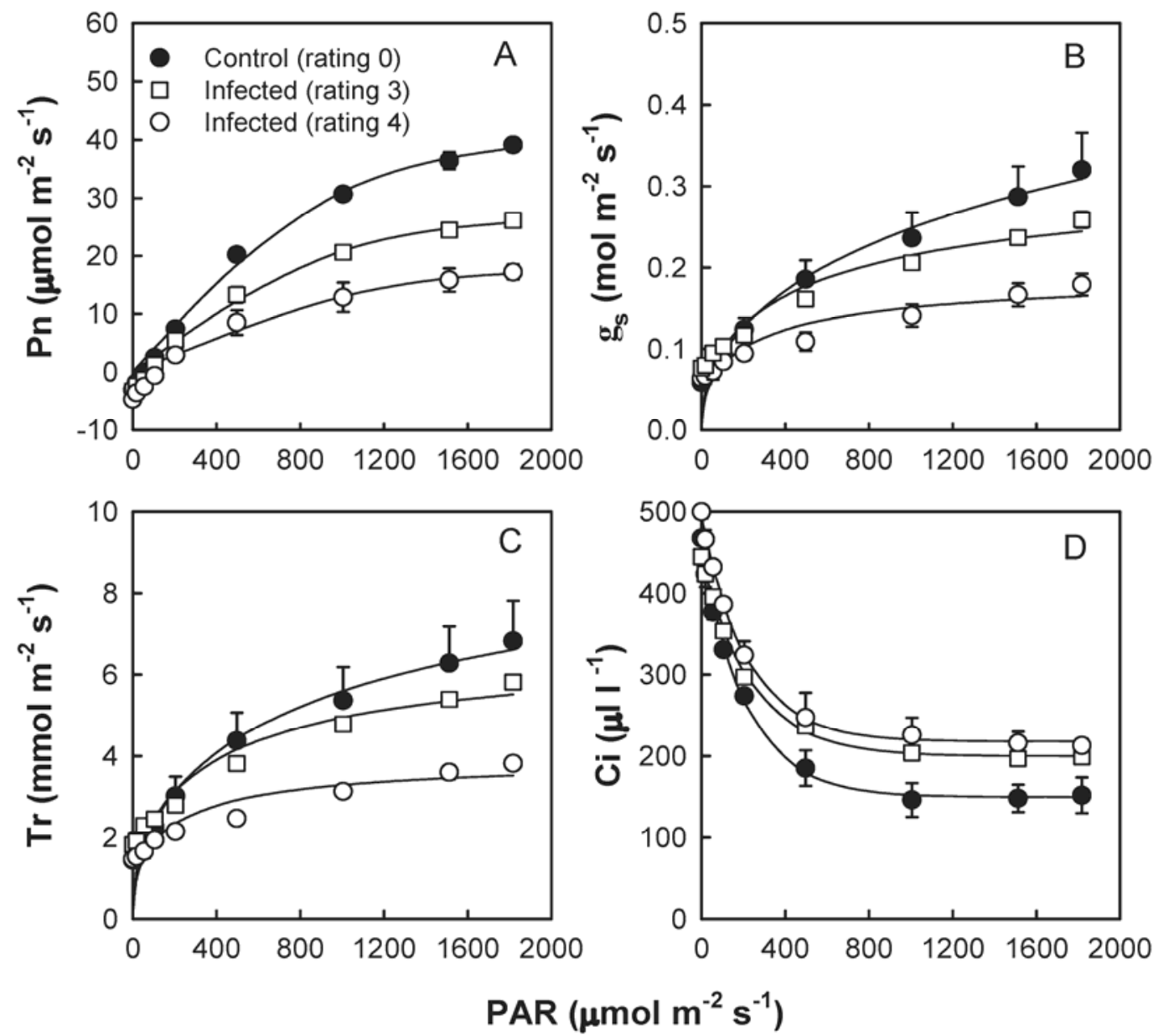

Fig. 4. Responses of $\mathbf{A}$, leaf net photosynthetic rate $(\mathrm{Pn}), \mathbf{B}$, stomatal conductance $\left(\mathrm{g}_{\mathrm{s}}\right), \mathbf{C}$, transpiration rate $(\mathrm{Tr})$, and $\mathbf{D}$, intercellular $\mathrm{CO}_{2}$ concentration $(\mathrm{Ci})$ to photosynthetically active radiation (PAR) as affected by orange rust disease rating. Measurements were taken at the infected portion of leaves 4 weeks after inoculation. Data are means \pm SE of three replicate plants from CP 72-2086 and CP 88-1762 $(n=6)$. 
and CFE (Table 2). Leaves with rust ratings of 3 and 4 had 13 and $52 \%$ higher Rd rates, respectively, than control leaves. Photosynthesis light compensation point (LCP) of leaves with rust rating 3 did not differ significantly from the control leaves. When the rust rating reached $4, \mathrm{LCP}$ of the disease-infected leaves increased to $119 \%(P<0.01)$ of control leaves. Leaf photosynthetic MQY and $\mathrm{CFE}$ significantly decreased as the rust rating increased. The effect of orange rust on CFE was greater than the effect on MQY. Compared with control leaves, MQY and CFE decreased by 19 and $51 \%$, respectively, for the disease infected leaves with a rust rating of 3, and by 29 and $70 \%$, respectively, for the infected leaves with a rust rating of 4 .

\section{Discussion}

For the first time it was demonstrated that leaf photosynthetic components responded to orange rust infection in sugarcane. Results of this study indicated that $\mathrm{Pn}, \mathrm{g}_{\mathrm{s}}$, and $\mathrm{Tr}$ measured on the rust-infected portion of inoculated leaves declined linearly, but $\mathrm{Ci}$ increased as the rust rating increased. The decrease in leaf Pn caused by orange rust on sugarcane agrees with previous work on rust-infected barley (Hordeum vulgare) (1), leek (36), wheat $(7,41)$, rice (6), bean (24), and soybean (Glycine max) (22). Although relationships of rust ratings with leaf SPAD index, Pn, $\mathrm{g}_{\mathrm{s}}$, $\mathrm{Tr}$, and $\mathrm{Ci}$ measured on infected leaf portions could be described using linear models, the sensitivity differed substantially among these physiological variables, and SPAD index and Pn were the physiological variables most sensitive to orange rust. The results of increased $\mathrm{Ci}$ due to orange rust suggested that low Pn for the rust-

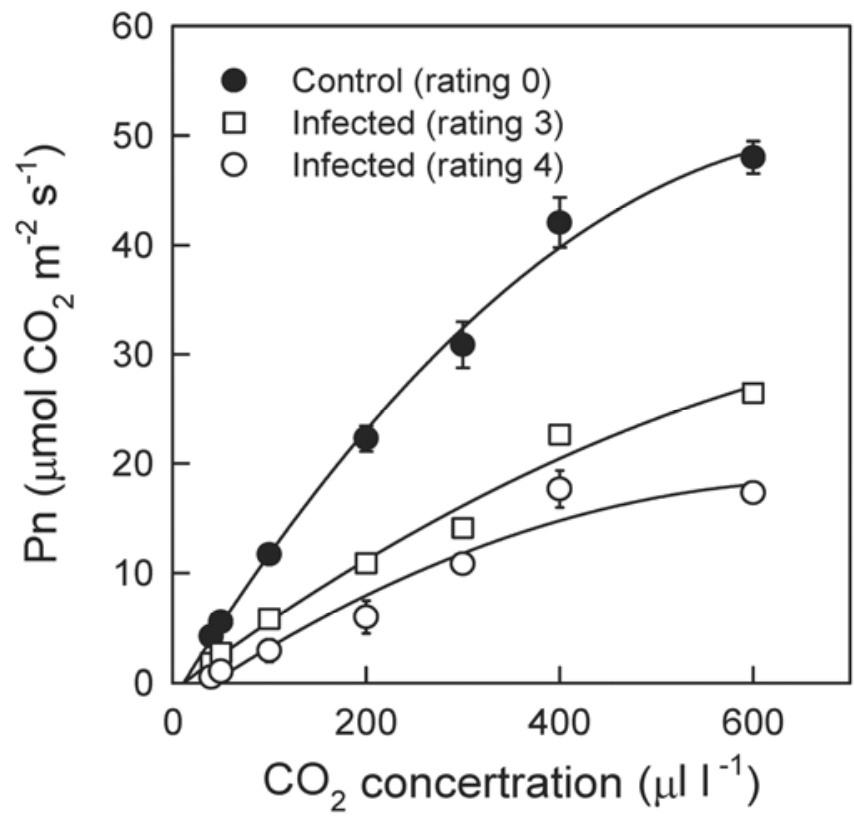

Fig. 5. Leaf net photosynthesis $(\mathrm{Pn})$ response to $\mathrm{CO}_{2}$ concentration as affected by orange rust disease rating. Measurements were taken at the infected portion of leaves about 4 weeks after inoculation. Data are means \pm SE of three replicate plants from CP 72-2086 and CP 88-1762 $(n=6)$. infected portion may be associated with nonstomatal factors, such as less chlorophyll content $(44,48)$ and photosynthesis enzyme activities $(36,44)$. It is well known that leaf photosynthesis is sensitive to VPD (12) or water stress $(16,45)$ and nonuniform stomatal closure induced by water stress can cause nonstomatal inhibition of photosynthesis $(12,16)$. Water stress was not a factor in the present study because all plants were well watered prior to measurements and VPD and leaf temperature were similar between treatments and did not change substantially during the experiment.

Photosynthetic rates measured on disease-free leaves of rustinfected plants, or on green regions of rust-infected leaves vary substantially in other crops. Fungal infection reduced the photosynthetic efficiency of the remaining green leaves in rice (6), bean (3), grape (27), and wheat $(7,35)$, but Pn measured on green tissue of infected leaves in leek did not differ from noninfected controls (36). In contrast, gross photosynthesis of barley leaves infected by the rust Puccinia hordei increased within areas of the leaf invaded by the fungus compared with control tissue (39). Net photosynthetic rate of green leaves in the upper canopy of infected broad bean plants was also significantly higher than that of the noninoculated control (28). The different responses of leaf Pn to rust infection in those studies were probably associated with rust pathogens, host plant species, disease severity, plant age, and/or experimental conditions. In the present study, Pn of green tissue on TVD leaves in inoculated plants did not differ from noninoculated control plants for the sugarcane genotypes tested, indicating there was not a systemic effect of a small portion of orange rust infection on Pn of noninfected leaves for inoculated plants (Table 1). Also, when Pn was measured on lower or upper portions of infected leaves, where disease symptoms were not observed, Pn did not correlate with rust rating (see Fig. 3). A lack of relationship between rust rating and Pn of lower/upper portions of infected sugarcane leaves is consistent with a report for leek (36). Our results did not support the hypothesis that orange rust infection would reduce Pn in green portions of infected leaves. One possible reason for this is that only small portions of leaves become infected following whorl inoculation.

Leaf photosynthesis is closely related to PAR until Pn reaches its maximum rate. The PAR changes frequently from day to day during the growing season and from time to time within each day. This is the first report on the effect of a rust disease on photosynthesis of $\mathrm{C} 4$ plants at different light intensities. To determine if orange rust affected sugarcane leaf Pn consistently at a wide range of PAR values, Pn responses to PAR for the control and infected leaves with orange rust ratings of 3 and 4 were measured. The Pn of rusted leaves decreased more under low PAR (45\% for rust rating 3 and $92 \%$ for rust rating 4 ) than under high PAR (33 and 57\%, respectively) compared with the noninfected control. This finding does not support reports in C3 plants of rice (6) or soybean (22). Leaf Pn of rice was more affected by leaf blast at saturated light than at low light (6). The reduction in leaf Pn of soybean due to soybean rust (Phakopsora pachyrhizi) infection was similar across a wide range of PAR values (22).

Data of Pn-light response curves further confirmed that orange rust had less effect on $g_{s}$ and $T r$ than on leaf Pn at most levels of PAR (Fig. 4) and that nonstomatal factors, such as chlorophyll content and/or relevant enzyme activities $(36,44,48)$, may contrib-

Table 2. Sugarcane leaf dark respiration rate, light compensation point, maximum quantum yield of $\mathrm{CO}_{2}$ assimilation, and carbon fixation efficiency as affected by orange rust rating ${ }^{2}$

\begin{tabular}{|c|c|c|c|}
\hline \multirow[b]{2}{*}{ Photosynthetic component } & \multicolumn{3}{|c|}{ Orange rust rating } \\
\hline & $\mathbf{0}$ (Control) & 3 & 4 \\
\hline Dark respiration rate $\left(\mu \mathrm{mol} \mathrm{CO} \mathrm{Cm}^{-2} \mathrm{~s}^{-1}\right)$ & $2.96 \pm 0.23 \mathrm{c}$ & $3.34 \pm 0.25 b$ & $4.50 \pm 0.10 \mathrm{a}$ \\
\hline Light compensation point $\left(\mu \mathrm{mol}\right.$ photon $\left.\mathrm{m}^{-2} \mathrm{~s}^{-1}\right)$ & $57.3 \pm 6.0 \mathrm{~b}$ & $63.3 \pm 21.7 b$ & $123.3 \pm 12.0 \mathrm{a}$ \\
\hline Maximum quantum yield $\left(\mu \mathrm{mol} \mathrm{CO}{ }_{2} \mu \mathrm{mol}^{-1}\right.$ photon $)$ & $0.052 \pm 0.002 \mathrm{a}$ & $0.042 \pm 0.001 \mathrm{~b}$ & $0.037 \pm 0.004 b$ \\
\hline Carbon fixation efficiency $\left(\mu \mathrm{mol} \mathrm{CO} 2 \mu \mathrm{l}\right.$ liter $\left.^{-1} \mathrm{CO}_{2}\right)$ & $0.115 \pm 0.007 \mathrm{a}$ & $0.056 \pm 0.000 \mathrm{~b}$ & $0.034 \pm 0.006 \mathrm{c}$ \\
\hline
\end{tabular}

${ }^{\mathrm{z}}$ Data are means $\pm \mathrm{SE}(n=6)$ of three replicate plants from CP 72-2086 and CP 88-1762. Means followed by the same letter within a row are not significantly different at $P=0.05$ level using LSD test. 
ute to reductions in Pn for rust-infected portions of sugarcane leaves. Stomatal conductance has previously been used as an indicator of plant water stress $(18,21,45)$. The results of the $g_{s}$ response to PAR indicate that $g_{s}$ is sensitive to light intensity even under a well-watered condition. When measuring $\mathrm{g}_{\mathrm{s}}$ for genotype screening or treatment comparison, weather conditions, especially light intensity, must be considered.

The increased sugarcane leaf $\mathrm{Rd}$ due to orange rust agrees with reports in other crops $(6,7,24,36,39)$. Dark respiration rate of rice leaves increased with increasing disease severity of leaf blast (6), and $\mathrm{Rd}$ rate within brown rust pustules on barley leaves was four times greater than values from control plants (39). Rusted leek leaf Rd rate in pustule regions had increased by six times compared with the $\mathrm{Rd}$ of the control leaves 21 days after inoculation (36). Although the increased Rd rates of rust-infected portions of sugarcane leaves in the present study were not as great as those reported in barley (39) and leek (36), significant differences were detected in $\mathrm{Rd}$ rates between the noninfected control and infected portions of leaves. The rate of $\mathrm{Rd}$ contributes significantly to total $\mathrm{CO}_{2}$ exchange in illuminated leaves (24). Increased Rd was partially responsible for reduced $\mathrm{Pn}$ observed in sugarcane leaves infected with the orange rust, because Pn was a product of leaf gross photosynthesis $\left(\mathrm{CO}_{2}\right.$ influx $)$ and dark respiration $\left(\mathrm{CO}_{2}\right.$ efflux $)$. Increased $\mathrm{Rd}$ of sugarcane orange rust infected leaves may be mainly associated with energy demands for host plant self defense or injury response to the disease and for urediniospore production during the sporulation phase. Fungal respiration might also have contributed to the increased $\mathrm{Rd}$ rate of rusted leaves, but we were unable to separate it from leaf Rd using a LI-COR 6400 photosynthesis system in this study. Additionally, orange rust significantly decreased MQY of $\mathrm{CO}_{2}$ assimilation and CFE of infected portions (Table 2), resulting in lower Pn under the same environmental conditions compared with the rust-free plants. Reductions in green leaf area and leaf Pn associated with orange rust resulted in sugarcane yield loss $(10,25,33)$.

Identification and quantitative determination of effects of a specific disease on the physiology of individual leaves are essential first steps for a broader understanding of disease damage and crop yield loss (5). This study revealed the physiological processes that lead to sugarcane yield loss in orange rust infected plants by measuring components of leaf photosynthesis. The results improve the understanding of orange rust disease etiology and physiological bases of sugarcane yield loss caused by orange rust. The quantitative relationships between orange rust ratings and photosynthesis components could be used for modeling the impact of rust on leaf photosynthesis (8) and plant growth in sugarcane.

\section{Acknowledgments}

We thank Philip Aria and Kay McCorkle for their valuable technical assistance and skilled data collection. We are grateful to Xinzhi Ni (USDA-ARS, Tifton, GA) and Jeff Hoy (Louisiana State University) for critical reviews and constructive comments on earlier versions of the manuscript.

\section{Literature Cited}

1. Ahmad, I., Farrar, J. F., and Whitbread, R. 1983. Photosynthesis and chloroplast functioning in leaves of barley infected with brown rust. Physiol. Plant Pathol. 23:411-416.

2. Barbasso, D., Jordão, H., Maccheroni, W., Boldini, J., Bressiani, J., and Sanguino, A. 2010. First report of Puccinia kuehnii, causal agent of orange rust of sugarcane, in Brazil. Plant Dis. 94:1170.

3. Bassanezi, R. B., Amorim, L., Bergamin Filho, A., Hau, B., and Berger, R. D. 2001. Accounting for photosynthetic efficiency of bean leaves with rust, angular leaf spot and anthracnose to assess crop damage. Plant Pathol. 50:443-452.

4. Bastiaans, L. 1991. Ratio between virtual and visual lesion size as a measure to describe reduction in leaf photosynthesis of rice due to leaf blast. Phytopathology 81:611-615.

5. Bastiaans, L., Rabbinge, R., and Zadoks, J. C. 1994. Understanding and modeling leaf blast effects on crop physiology and yield. Pages 357-380 in: Rice Blast Disease. R. S. Zeigler, S. A. Leong, and P. S. Teng, eds. CAB International, Wallingford, UK.

6. Bastiaans, L., and Roumen, E. C. 1993. Effect on leaf photosynthetic rate by leaf blast for rice cultivars with different types and levels of resistance. Euphytica 66:81-87.
7. Bethenod, O., Huber, L., and Slimi, H. 2001. Photosynthetic response of wheat to stress induced by Puccinia recondita and post-infection drought. Photosynthetica 39:581-590.

8. Bethenod, O., Le Corre, M., Huber, L., and Sache, I. 2005. Modelling the impact of brown rust on wheat crop photosynthesis after flowering. Agric. For. Meteorol. 131:41-53.

9. Biemelt, S., and Sonnewald, U. 2006. Plant-microbe interactions to probe regulation of plant carbon metabolism. J. Plant Physiol. 163:307-318.

10. Braithwaite, K. S., Croft, B. J., Magarey, R. C., and Scharaschkin, T. 2009. Phylogenetic placement of the sugarcane orange rust pathogen Puccinia kuehnii in a historical and regional context. Aust. Plant Pathol. 38:380-388.

11. Buchanan, B. B., Hutchinson, S. W., Magyarosy, A. C., and Montalbini, P. 1981. Photosynthesis in healthy and diseased plants. Pages 13-28 in: Effects of Disease on the Physiology of the Growing Plant. P. G. Ayres, ed. Cambridge University Press, Cambridge.

12. Bunce, J. A. 1988. Nonstomatal inhibition of photosynthesis by water stress. Reduction in photosynthesis at high transpiration rate without stomatal closure in field grown tomato. Photosynth. Res. 18:357-362.

13. Chavarría, E., Subirós, F., Vega, J., Ralda, G., Glynn, N. C., Comstock, J. C., and Castlebury, L. A. 2009. First report of orange rust of sugarcane caused by Puccinia kuehnii in Costa Rica and Nicaragua. Plant Dis. 93:425.

14. Comstock, J. C., Sood, S. G., Glynn, N. C., Shine, J. M., Jr., McKemy, J. M., and Castlebury, L. A. 2008. First report of Puccinia kuehnii, causal agent of orange rust of sugarcane, in the United States and Western Hemisphere. Plant Dis. 92:175.

15. Davidson, R. W., Milligan, S. B., Glaz, B., Comstock, J. C., Hu, C. J Glynn, N. C., Edmé, S. J., Holder, D. G., Gilbert, R. A., Sood, S., del Blanco, I. A., and Zhao, D. 2011. Registration of 'CPCL 99-4455' sugarcane. J. Plant Reg. 5:54-61.

16. Downton, W. J. S., Loveys, B. R., and Grant, W. J. R. 1988. Non-uniform stomatal closure induced by water stress causes putative non-stomatal inhibition of photosynthesis. New Phytol. 110:503-509.

17. Flores, R. C., Loyo, J. R., Ojeda, R. A., Rangel, O. C. A., Cerón, F. A., Márquez, W., Guerra-Moreno, A. S., Hernandez-Ibarra, H. M., González, R. E., Castlebury, L. A., Dixon, L. J., Glynn, N. C., Comstock, J. C., Flynn, J., and Amador, J. 2009. First report of orange rust of sugarcane caused by Puccinia kuehnii in Mexico, El Salvador, and Panama. Plant Dis. 93:1347.

18. Gardner, F. P., Pearce, R. B., and Mitchell, R. L. 1985. Physiology of Crop Plants. Iowa State University Press, Ames.

19. Glaz, B., Miller, J. D., Deren, C. W., Tai, P. Y. P., Shine, J. M., Jr., and Comstock, J. C. 2000. Registration of 'CP 89-2143' sugarcane. Crop Sci. 40:577.

20. Glynn, N. C., Dixon, L. J., Castlebury, L. A., Szabo, L. J., and Comstock, J. C. 2010. PCR assays for the sugarcane rust pathogens Puccinia kuehnii and P. melanocephala and detection of a SNP associated with geographic distribution in P. kuehnii. Plant Pathol. 59:703-711.

21. Jones, H. G. 1999. Use of infrared thermometry for estimation of stomatal conductance as a possible aid to irrigation scheduling. Agric. For. Meteorol. 95:139-149.

22. Kumudini, S., Prior, E., Omielan, J., and Tollenaar, M. 2008. Impact of Phakopsora pachyrhizi infection on soybean leaf photosynthesis and radiation absorption. Crop Sci. 48:2343-2350.

23. Livne, A. 1964. Photosynthesis in healthy and rust-affected plants. Plant Physiol. 39:614-621.

24. Lopes, D. B., and Berger, R. D. 2001. The effects of rust and anthracnose on the photosynthetic competence of diseased bean leaves. Phytopathology 91:212-220.

25. Magarey, R. C., Croft, B. J., and Willcox, T. G. 2001. An epidemic of orange rust on sugarcane in Australia. Proc. Int. Soc. Sugar Cane Technol. 24:410-416.

26. Miller, J. D, Tai, P. Y. P., Glaz, B., Dean, J. L., and Kang, M. S. 1984. Registration of 'CP 72-2086' sugarcane. Crop Sci. 24:210.

27. Moriondo, M., Orlandini, S., Giuntoli, A., and Bindi, M. 2005. The effect of downy and powdery mildew on grapevine (Vitis vinifera L.) leaf gas exchange. J. Phytopathol. 153:350-357.

28. Murray, D. C., and Walters, D. R. 1992. Increased photosynthesis and resistance to rust infection in upper, uninfected leaves of rusted broad bean ( $\mathrm{Vi}$ cia faba L.). New Phytol. 120:235-242.

29. Ögren, E., and Even, J. R. 1993. Photosynthetic light-response curves: I. The influence of $\mathrm{CO}_{2}$ partial pressure and leaf inversion. Planta 189:182-190.

30. Ovalle, W., Comstock, J. C., Glynn, N. C., and Castlebury, L. A. 2008. First report of Puccinia kuehnii, causal agent of orange rust of sugarcane, in Guatemala. Plant Dis. 92:973.

31. Pérez-Vicente, L., Martín-Triana, E. L., Barroso, F., Martínez-de la Parte, E., Borrás-Hidalgo, O., and Hernández Estévez, I. 2010. Definitive identification of orange rust of sugarcane caused by Puccinia kuehnii in Cuba. Plant Pathol. 59:804.

32. Rabbinge, R., and Rijsdijk, F. H. 1981. Disease and crop physiology: A modeler's point of view. Pages 201-221 in: Effects of Disease on the Physiology of the Growing Plant. P. G. Ayres, ed. Cambridge University Press, Cambridge.

33. Raid, R. N., Comstock, J. C., and Glynn, N. C. 2010. A comparison of orange rust epidemics in Florida during 2008 and 2009 and their influence on yield. Sugar J. 6:28. 
34. Rice, R., Baucum, L., and Glaz, B. 2009. Sugarcane variety census: Florida 2008. Sugar J. 7:6-12.

35. Robert, C., Bancal, M. O., Lannou, C., and Ney, B. 2006. Quantification of the effects of Septoria tritici blotch on wheat leaf gas exchange with respect to lesion age, leaf number, and leaf nitrogen status. J. Exp. Bot. 57:225-234.

36. Roberts, A. M., and Walters, D. R. 1988. Photosynthesis in discrete regions of leek leaves infected with the rust, Puccinia allii Rud. New Phytol. 110:371-376.

37. Roloff, I., Scherm, H., and van Iersel, M. W. 2004. Photosynthesis of blueberry leaves as affected by Septoria leaf spot and abiotic leaf damage. Plant Dis. 88:397-401.

38. SAS Institute. 2003. SAS System for Windows Release 9.1. SAS Institute, Cary, NC.

39. Scholes, J. D., and Farrar, J. F. 1986. Increased rates of photosynthesis in localised regions of a barley leaf infected with brown rust. New Phytol. 104:601-612.

40. Sood, S. G., Comstock, J. C., and Glynn, N. C. 2009. Leaf whorl inoculation method for screening sugarcane rust resistance. Plant Dis. 93:13351340 .

41. Statler, G. D. 1988. Apparent photosynthesis in health and Puccinia recondite infected wheat plants. Can. J. Plant Physiol. 10:203-206.

42. Stirling, C. M., Aguilera, C., Baker, N. R., and Long, S. P. 1994. Changes in the photosynthetic light response curve during leaf development of field grown maize with implications for modeling canopy photosynthesis. Photosynth. Res. 43:217-225.

43. Tai, P. Y. P., Shine, J. M., Jr., Deren, C. W., Glaz, B., Miller, J. D., and Comstock, J. C. 1997. Registration of 'CP 88-1762' sugarcane. Crop Sci. $37: 1388$.

44. Tang, X., Rolfe, S. A., and Scholes, J. D. 1996. The effect of Albugo Candida (white blister rust) on the photosynthetic and carbohydrate metabolism of leaves of Arabidopsis thaliana. Plant Cell Environ. 19:967-975.

45. Zhao, D., Glaz, B., and Comstock, J. 2010. Sugarcane response to waterdeficit stress during early growth on organic and sand soils. Am. J. Agric. Biol. Sci. 5:403-414.

46. Zhao, D., Reddy, K. R., and Kakani, V. G. 2005. Nitrogen deficiency effects on leaf chlorophyll concentration, photosynthesis, and spectral reflectance properties of sorghum. Eur. J. Agron. 22:391-403.

47. Zhao, D., Reddy, K. R., Kakani, V. G., Read, J. J., Razack, M., and Gao, W. 2004. Leaf and canopy photosynthesis characteristics of cotton (Gossypium hirsutum $\mathrm{L}$.) under elevated $\mathrm{CO}_{2}$ concentration and UV-B radiation. J. Plant Physiol. 161:581-590.

48. Zitko, S. E., Statler, G. D., and Nutter, F. W., Jr. 1985. Chlorophyll of wheat leaves with differences in leaf rust severity and reaction type. Can. J. Plant Pathol. 7:146-150. 